\title{
Óbitos de idosos no trânsito da Cidade de São Paulo, 2011 a 2015
}

\section{Deaths of elderly people in the traffic of São Paulo City, 2011 to 2015 Elizabeth Mascarelli de Almeida ${ }^{1}$, Mônica Mendonça Lima², Maria Luiza Cavallari ${ }^{3}$}

DOI: http://dx.doi.org/10.11606/issn.2317-2770.v22i2p95-99

\begin{abstract}
Almeida EM, Lima MM, Cavallari ML. Óbitos de idosos no trânsito da Cidade de São Paulo, 2011 a 2015. Saúde, Ética \& Justiça. 2017;22(2):95-99.

RESUMO: A população brasileira está vivendo mais e, consequentemente, a ocorrência de acidentes envolvendo idosos aumenta. Este trabalho visa conhecer o perfil dos idosos mortos no trânsito da maior metrópole brasileira - São Paulo. De 2011 a 2015, 1.119 maiores de 60 anos morreram no trânsito paulistano. Dessas pessoas, 59,2\% eram homens; 59,5\% eram aposentados; $73,7 \%$ tinham baixa escolaridade e $86,6 \%$ estavam como pedestres na ocasião do acidente. A maioria (64,5\%) se acidentou durante o dia. Na cidade de São Paulo os idosos pedestres têm o dobro de chance de morrer no trânsito quando comparados ao Brasil como um todo.
\end{abstract}

PALAVRAS CHAVE: Idoso; Acidentes de Trânsito; Mortalidade.

\footnotetext{
1. Médica do Trabalho e Médica de Tráfego

2. Faculdade de Medicina da Universidade de São Paulo - doutoranda. Médica de Tráfego.

3. Instituto Adolfo Lutz - doutoranda em Ciências.

Endreço para correspondência: Maria Luiza Cavallari, e-mail: malu_bio@hotmail.com
} 


\section{INTRODUÇÃO}

A população brasileira está envelhecendo. A exemplo do que ocorre com as nações desenvolvidas, a redução das doenças infecciosas agudas pela vacinação e saneamento básico, a diminuição do uso do tabaco e a melhora do poder aquisitivo estão entre as causas da maior longevidade dos brasileiros.

A nossa pirâmide populacional, que era em forma de triângulo na década de 80 , está diminuindo na base e aumentando no ápice: os maiores de 60 anos, segundo pesquisa do IBGE de $2015^{1}$, eram $14,3 \%$ dos brasileiros.

Há várias classificações de idosos mundo afora. A adotada pelo Instituto de Pesquisa Econômica Aplicada (IPEA) considera idosos jovens aqueles que têm entre 60 e 70 anos de idade; medianamente idosos a partir de 70 até 80 anos; e muito idosos acima de $80^{2}$.

O número de internações entre os maiores de 60 anos por acidentes de trânsito no ano 2011 no Brasil foi de 12.002 (taxa de 56,4/100.000 hab.) e o número de óbitos, 6.248 (taxa de 29,4/100.000 hab) ${ }^{3}$.

O presente trabalho visa conhecer o cenário das mortes de idosos no trânsito da Cidade de São Paulo.

\section{MATERIAL E MÉTODOS}

A partir de análise no Banco de Dados do Relatório de Acidentes Fatais da Companhia de Engenharia do Tráfego (CET) no período de 2011 a $2015^{4}$ filtraram-se os dados mais relevantes relacionados aos óbitos por acidente de trânsito entre aqueles de 60 anos ou mais.

Adotou-se o conceito de idoso do Estatuto do Idoso, Lei $n^{\circ} 10.741$, de $1^{\circ}$ de outubro de $2003^{5}$ como o indivíduo com idade igual ou superior a 60 anos e as subclasses do IPEA - idosos jovens (60 a menor que 70), medianamente idosos (70 a menor que 80 ) e muito idosos (acima de 80 anos) $)^{3}$.

As informações utilizadas foram aquelas relacionadas ao sexo, idade, escolaridade, ocupação, posição da vítima no contexto de trânsito (como pedestre, condutor ou passageiro de carro, ônibus etc), dia da semana e horário do acidente.

\section{RESULTADOS}

Nos cinco anos analisados ocorreram 5.990 mortes por acidente de trânsito na cidade de São Paulo, sendo $40 \%$ de menores de 30 anos, $41 \%$ de pessoas com idades de 30 a 59 anos e $19 \%$ de maiores de 60 anos, conforme dados da Tabela 1.

Tabela 1. Estratificação etária dos mortos por acidente de trânsito. Cidade de São Paulo, 2011 a 2015

\begin{tabular}{llllllll}
\hline Faixa etária & $\mathbf{2 0 1 1}$ & $\mathbf{2 0 1 2}$ & $\mathbf{2 0 1 3}$ & $\mathbf{2 0 1 4}$ & $\mathbf{2 0 1 5}$ & Total & $\mathbf{\%}$ \\
\hline 0 a 9 & 20 & 31 & 25 & 17 & 19 & 112 & $1,9 \%$ \\
10 a 19 & 160 & 136 & 146 & 179 & 130 & 751 & $12,5 \%$ \\
20 a 29 & 370 & 317 & 273 & 311 & 238 & 1509 & $25,2 \%$ \\
30 a 39 & 235 & 238 & 194 & 223 & 159 & 1049 & $17,5 \%$ \\
40 a 49 & 184 & 160 & 167 & 162 & 131 & 804 & $13,4 \%$ \\
50 a 59 & 147 & 127 & 101 & 120 & 107 & 602 & $10,1 \%$ \\
60 a 69 & 116 & 84 & 90 & 95 & 82 & 467 & $7,8 \%$ \\
70 a 79 & 74 & 78 & 83 & 75 & 68 & 378 & $6,3 \%$ \\
80 a 89 & 49 & 43 & 60 & 48 & 43 & 243 & $4,1 \%$ \\
90 e + & 4 & 9 & 5 & 6 & 7 & 31 & $0,5 \%$ \\
s/informação & 10 & 6 & 8 & 13 & 7 & 44 & $0,7 \%$ \\
\hline Total & $\mathbf{1 3 6 9}$ & $\mathbf{1 2 2 9}$ & $\mathbf{1 1 5 2}$ & $\mathbf{1 2 4 9}$ & $\mathbf{9 9 1}$ & $\mathbf{5 9 9 0}$ & $\mathbf{1 0 0 , 0 \%}$ \\
\hline Fonte: Relatório de Acidentes Fatais - CET, 2011 a 2015 & & & & & \\
& & & & & & &
\end{tabular}

Considerando-se especificamente a população com 60 anos ou mais, foram 1.119 óbitos, dos quais $59,2 \%$ eram de homens e $40,8 \%$ de mulheres.
Os óbitos entre idosos jovens foram 467 (41,7\%); de moderadamente idosos, $378(33,8 \%)$ e de muito idosos, $274(24,5 \%)$ - Tabela 2. 
Tabela 2. Estratificação dos idosos mortos por acidente de transito. Cidade de São Paulo, 2011 a 2015

\begin{tabular}{lllllll}
\hline $\begin{array}{l}\text { Faixa } \\
\text { etária }\end{array}$ & \multicolumn{2}{c}{ Sexo } & \multicolumn{2}{c}{ \% Sexo } & \multicolumn{2}{c}{$\%$ Faixa etária } \\
& F & \% M & \% F & Total & \% \\
\hline $60<65$ & 162 & 83 & $14,5 \%$ & $7,4 \%$ & 245 & $21,9 \%$ \\
$65<70$ & 134 & 88 & $12,0 \%$ & $7,9 \%$ & 222 & $19,8 \%$ \\
$70<75$ & 113 & 95 & $10,1 \%$ & $8,5 \%$ & 208 & $18,6 \%$ \\
$75<80$ & 97 & 73 & $8,7 \%$ & $6,5 \%$ & 170 & $15,2 \%$ \\
$80<85$ & 89 & 60 & $8,0 \%$ & $5,4 \%$ & 149 & $13,3 \%$ \\
$85<90$ & 47 & 47 & $4,2 \%$ & $4,2 \%$ & 94 & $8,4 \%$ \\
90 e + & 21 & 10 & $1,9 \%$ & $0,9 \%$ & 31 & $2,8 \%$ \\
\hline Total & $\mathbf{6 6 3}$ & $\mathbf{4 5 6}$ & $\mathbf{5 9 , 2 \%}$ & $\mathbf{4 0 , 8 \%}$ & $\mathbf{1 1 1 9}$ & $\mathbf{1 0 0 , 0 \%}$ \\
\hline
\end{tabular}

Fonte: Relatório de Acidentes Fatais - CET, 2011 a 2015

$73,3 \%$ dos idosos mortos no trânsito da Cidade de São Paulo tinham escolaridade de até $1^{\circ}$ grau completo e somente $6,4 \%$ tinham superior completo - Tabela 3 .

Tabela 3. Escolaridade dos idosos, vítimas de acidentes de trânsito. Cidade de São Paulo, 2011 a 2015

\begin{tabular}{lllll}
\hline Escolaridade & $\mathbf{M}$ & $\mathbf{F}$ & Total & $\mathbf{\%}$ \\
\hline Analfabeto & 44 & 47 & 91 & $8,1 \%$ \\
$1^{\text {o }}$ grau incompleto & 258 & 185 & 443 & $39,6 \%$ \\
$1^{\text {o }}$ grau completo & 171 & 115 & 286 & $25,6 \%$ \\
$2^{\text {o }}$ grau incompleto & 9 & 5 & 14 & $1,3 \%$ \\
$2^{\text {o }}$ grau completo & 78 & 52 & 130 & $11,6 \%$ \\
Superior incompleto & 3 & 5 & 8 & $0,7 \%$ \\
Superior completo & 48 & 24 & 72 & $6,4 \%$ \\
S/informação & 52 & 23 & 75 & $6,7 \%$ \\
\hline Total & $\mathbf{6 6 3}$ & $\mathbf{4 5 6}$ & $\mathbf{1 1 1 9}$ & $\mathbf{1 0 0 , 0 \%}$ \\
\hline Fonte: Relatório de Acidentes Fatais - CET, 2011 a 2015
\end{tabular}

Entre os mortos, quase $60 \%$ eram aposentados e cerca de 10\%, "do lar" (mulheres). Profissões que apareceram uma única vez foram agrupadas em outras ocupações - Tabela 4.

Tabela 4. Ocupação dos idosos vítimas de acidentes de trânsito. Cidade de São Paulo 2011 a 2015

\begin{tabular}{lll}
\hline Ocupação & $\mathbf{N}^{\mathbf{0}}$ & $\mathbf{\%}$ \\
\hline aposentados/pensionistas & 666 & $59,5 \%$ \\
"do lar" & 110 & $9,8 \%$ \\
autônomos & 28 & $2,5 \%$ \\
pedreiros & 27 & $2,4 \%$ \\
comerciantes & 24 & $2,1 \%$ \\
motoristas & 22 & $2,0 \%$ \\
auxiliares serviços & 17 & $1,5 \%$ \\
vigilantes/ zelares & 14 & $1,3 \%$ \\
domesticas/diaristas & 13 & $1,2 \%$ \\
ajudantes gerais & 12 & $1,1 \%$ \\
pintores & 10 & $0,9 \%$ \\
moradores rua & 9 & $0,8 \%$ \\
professores & 8 & $0,7 \%$ \\
outras ocupações & 137 & $12,2 \%$ \\
s/informação & 22 & $2,0 \%$ \\
\hline Total & 119 & $100,0 \%$ \\
\hline Fet & &
\end{tabular}

Fonte: Relatório de Acidentes Fatais - CET, 2011 a 2015

Em 86,6\% dos óbitos, as vítimas foram pedestres; ocupantes de automóveis foram 8,9\%; ocupantes de ônibus, $1,6 \%$ e ocupantes de caminhão, $0,6 \%$. Motociclistas e ciclistas perfizeram 1,2 e 1,3\% respectivamente - Tabela 5 .

Tabela 5. Características das vítimas idosas mortas por acidente de transito. Cidade de São Paulo 2011 a 2015

\begin{tabular}{|c|c|c|c|c|c|c|c|c|c|c|c|c|c|c|c|c|c|c|c|}
\hline \multirow[t]{2}{*}{ Vítimas } & \multicolumn{2}{|c|}{ pedestre } & \multicolumn{2}{|c|}{$\begin{array}{c}\text { condutor } \\
\text { automóvel }\end{array}$} & \multicolumn{2}{|c|}{$\begin{array}{l}\text { passageiro } \\
\text { automóvel }\end{array}$} & \multicolumn{2}{|c|}{$\begin{array}{c}\text { condutor } \\
\text { ônipus }\end{array}$} & \multicolumn{2}{|c|}{$\begin{array}{c}\text { passageiro } \\
\text { onnipus }\end{array}$} & \multicolumn{2}{|c|}{$\begin{array}{l}\text { condutor } \\
\text { caminhão }\end{array}$} & \multicolumn{2}{|c|}{$\begin{array}{l}\text { passageiro } \\
\text { caminhão }\end{array}$} & \multicolumn{2}{|c|}{ motociclista } & \multicolumn{2}{|c|}{ ciclista } & \multirow[t]{2}{*}{ Total } \\
\hline & $\mathbf{M}$ & F & $\mathbf{M}$ & F & M & $\mathbf{F}$ & $\mathbf{M}$ & F & M & F & $\mathbf{M}$ & F & M & F & M & F & $\mathbf{M}$ & F & \\
\hline $60<65$ & 128 & 75 & 16 & 3 & 1 & 3 & 1 & 0 & 1 & 1 & 1 & 0 & 1 & 1 & 7 & 0 & 6 & 0 & 245 \\
\hline $65<70$ & 108 & 75 & 13 & 1 & 4 & 8 & 0 & 0 & 1 & 4 & 0 & 0 & 1 & 0 & 3 & 0 & 4 & 0 & 222 \\
\hline $70<75$ & 95 & 81 & 9 & 4 & 2 & 9 & 0 & 0 & 3 & 1 & 1 & 0 & 1 & 0 & 1 & 0 & 2 & 0 & 209 \\
\hline $75<80$ & 90 & 69 & 3 & 2 & 1 & 1 & 0 & 0 & 2 & 1 & 0 & 0 & 0 & 0 & 0 & 0 & 0 & 0 & 169 \\
\hline $80<85$ & 79 & 56 & 5 & 1 & 0 & 3 & 0 & 0 & 1 & 0 & 0 & 0 & 0 & 0 & 2 & 0 & 2 & 0 & 149 \\
\hline $85<90$ & 44 & 43 & 2 & 1 & 0 & 3 & 0 & 0 & 1 & 0 & 0 & 0 & 0 & 0 & 0 & 0 & 0 & 0 & 94 \\
\hline $90 \mathrm{e}+$ & 17 & 9 & 2 & 0 & 1 & 1 & 0 & 0 & 1 & 0 & 0 & 0 & 0 & 0 & 0 & 0 & 0 & 0 & 31 \\
\hline Total & 561 & 408 & 50 & 12 & 9 & 28 & 1 & 0 & 10 & 7 & 2 & 0 & 3 & 1 & 13 & 0 & 14 & 0 & 1119 \\
\hline$\%$ & $50,1 \%$ & $36.5 \%$ & $4.5 \%$ & $1.1 \%$ & $0.8 \%$ & $2,5 \%$ & $0,1 \%$ & $0,0 \%$ & $0.9 \%$ & $0.6 \%$ & $0.2 \%$ & $0,0 \%$ & $0.3 \%$ & $0,1 \%$ & $1.2 \%$ & $0,0 \%$ & $1.3 \%$ & $0,0 \%$ & $100.0^{\circ}$ \\
\hline
\end{tabular}


A distribuição de óbitos pelos dias da semana foi relativamente homogênea, e o fim de semana representou $26 \%$ dos casos - Tabela. 6 .

Tabela 6. Dia da semana dos óbitos por acidente de transito em idosos. Cidade de São Paulo 2011 a 2015

\begin{tabular}{|c|c|c|}
\hline Dia da semana & $\mathrm{N}^{0}$ & $\%$ \\
\hline domingo & 128 & $11,4 \%$ \\
\hline $2^{a}$ feira & 156 & $13,9 \%$ \\
\hline $3^{a}$ feira & 153 & $13,7 \%$ \\
\hline $4^{a}$ feira & 182 & $16,3 \%$ \\
\hline $5^{a}$ feira & 173 & $15,5 \%$ \\
\hline $6^{a}$ feira & 154 & $13,8 \%$ \\
\hline sábado & 162 & $14,5 \%$ \\
\hline s/informação & 11 & $1,0 \%$ \\
\hline Total & 1119 & $100,0 \%$ \\
\hline
\end{tabular}

Quanto ao horário, 64,5\% das mortes ocorreram durante o dia (das 6:00 às 18:00 horas) - Tabela 7.

Tabela 7. Horário dos óbitos por acidente de trânsito em idosos Cidade de São Paulo 2011 a 2015

\begin{tabular}{lll}
\hline Horário do dia & $\mathbf{N}^{\mathbf{0}}$ & $\mathbf{\%}$ \\
\hline 0:00 - 5:59 & 66 & $5,9 \%$ \\
6:00-11:59 & 350 & $31,3 \%$ \\
12:00-17:59 & 372 & $33,2 \%$ \\
18:00-23:59 & 271 & $24,2 \%$ \\
s/inform. & 60 & $5,4 \%$ \\
\hline Total & $\mathbf{1 1 1 9}$ & $\mathbf{1 0 0 , 0 \%}$ \\
\hline
\end{tabular}

Fonte: Relatório de Acidentes Fatais - CET, 2011 a 2015

\section{DISCUSSÃO}

Quase 1/5 dos óbitos por acidente de trânsito na Cidade de São Paulo ocorreu na população com idade igual ou maior que 60 anos. Os muito idosos (maiores de 80 ) representaram $5 \%$ das mortes. Além disso, foi observado que os homens são a maioria $(59,2 \%)$, exceto faixa etária de 85 a 90 anos.

A escolaridade de homens e de mulheres mortos no trânsito foi bem parecida - aqueles com baixa escolaridade morreram mais. Os pedestres foram a maioria absoluta de mortos entre a população estudada $(86,6 \%)$, seguidos de longe por ocupantes de automóveis.

Considerando-se que na cidade de São Paulo havia $12 \%$ de idosos durante o período estudado ${ }^{6}$, chama a atenção o contingente de $19 \%$ de mortes no trânsito correspondendo a essa população. Estudo brasileiro de 2011 encontrou menos de $15 \%$ dos óbitos entre os idosos ${ }^{7}$, ou seja: na cidade de São Paulo o idoso parece estar mais vulnerável a morrer por acidente de trânsito do que no Brasil como um todo.

A baixa escolaridade (até $1^{\circ}$ grau) esteve presente entre mais de $73,3 \%$ dos óbitos registrados - vale a pena estudar se o acidente de trânsito, bem como outros agravos, tem na pobreza um dos principais fatores associados.

Em diversos estudos relacionados a acidentes de tráfego, o homem aparece como o que mais se acidenta e morre por esta causa ${ }^{8-10}$. Neste estudo não foi diferente: mesmo entre idosos a razão de masculinidade ficou em 1,5:1 (ou seja, incidência 50\% maior para homens). Somente homens idosos morreram na condução de bicicletas, motocicletas, ônibus ou caminhões. As mulheres idosas também foram a minoria como condutoras de automóveis mortas no trânsito - 12 dos 62 casos $(19,4 \%)$.

Os pedestres, dentre os idosos, foram os mais suscetíveis a morrer no trânsito de São Paulo: velocidade, desrespeito às leis de trânsito e a maior fragilidade dos idosos, tanto do ponto de vista físico como cognitivo, devem concorrer para este resultado. Mais uma vez notamos a discrepância da cidade em relação ao Brasil: - em levantamento realizado em $2011^{7}$, menos de $45 \%$ das mortes de idosos no trânsito foram de pedestres; no presente estudo, $86,6 \%$ dos idosos mortos no trânsito paulistano eram pedestres.

Entre os idosos, pedestres, homens e com baixa escolaridade foram os que mais sucumbiram ao trânsito paulistano - foram 412 pessoas ( $36,8 \%$ dos óbitos).

\section{CONSIDERAÇÕES FINAIS}

Condutores de veículos maiores de 60 anos, ainda que, neste estudo, tenham representado menos de $10 \%$ dos óbitos (quando considerada a condução de qualquer tipo de veículo) necessitam sempre de boa avaliação para ter a permissão para dirigir, frente às limitações que a idade avançada impõe. A renovação da Carteira Nacional de Habilitação $(\mathrm{CNH})$ com intervalo menor e a adaptação dos veículos são alternativas que diminuem os riscos deste público, muitas vezes, física e cognitivamente prejudicado.

Especialmente na cidade de São Paulo, quando comparamos com dados do Brasil em geral, observamos que os idosos estão mais sujeitos a morrer por acidente de trânsito, principalmente os homens, na situação de pedestres. Vale a pena investigar se além da vulnerabilidade própria do idoso, que é mais lento, tende a ter visão e audição reduzidas, entram em jogo outros fatores como o uso de álcool ou de medicamentos que afetem a cognição.

Sugere-se que sejam adotadas ações educativas, que visem tanto aos idosos como aos motoristas, na tentativa de reduzir a violência no trânsito e um contingente de mortes evitáveis. 
Almeida EM, Lima MM, Cavallari ML. Deaths of elderly people in the traffic of São Paulo City, 2011 to 2015. Saúde, Ética \& Justiça. 2017;22(2):95-99.

ABSTRACT: The Brazilian population is living longer and, consequently, the occurrence of traffic accidents involving elderly people is increasing. This study aims to assess the profile of the elderly people that died due to traffic accidents in São Paulo, the largest Brazilian metropolis. From 2011 to 2015, 1,119 people aged over 60 died in traffic accidents in São Paulo. Among them, $59.2 \%$ were men; $59.5 \%$ were retired; $73.7 \%$ had low schooling; $86.6 \%$ were pedestrians. The majority of the accidents $(64.5 \%)$ occurred during the day. In the city of São Paulo, elderly pedestrians have twice the chance of dying in traffic accidents, when compared to Brazil as a whole.

KEY WORDS: Aged; Accidents, Traffic; Mortality.

Agradecimentos: À Equipe do Departamento de Estudos e Pesquisa de Tráfego da Companhia de Engenharia de Tráfego (CET) pela cessão dos dados utilizados nesse trabalho.

\section{REFERÊNCIAS}

1. Portal Brasil. Em 10 anos, cresce número de idosos no Brasil. Governo do Brasil [Internet]. Brasília, DF; 2016 [acesso em 2017 jan. 28]. Disponível em http://www.brasil. gov.br/economia-e-emprego/2016/12/em-10-anos-crescenumero-de-idosos-no-brasil

2. Instituto de Pesquisa Econômica Aplicada (IPEA) [homepage na internet]. Brasília, DF [acesso em 2017 jan. 28]. Disponível em: www.ipea.gov.br

3. Mello Jorge MHP, Adura FE. O idoso no trânsito. Rev Abramet. 2015;32(1):17-25.

4. Companhia de Engenharia de Tráfego (CET). Relatórios de Acidentes Fatais 2011 a 2015 [Internet]. São Paulo; 2015 [acesso em 2017 fev. 02]. Disponível em http://www.cetsp. com.br/sobre-a-cet/relatorios-corporativos.aspx

5. Brasil, Presidência da República, Casa Civil, Subchefia para Assuntos Jurídicos. Lei ${ }^{\circ} 10.741$, de $1^{\circ}$ de outubro de 2003. Dispõe sobre o Estatuto do Idoso e dá outras providências [Internet]. Brasília, DF; 2003 [acesso em 2017 fev. 02]. Disponível em http://www.planalto.gov.br/ ccivil_03/leis/2003/L10.741.htm

6. São Paulo, Prefeitura de São Paulo, Desenvolvimento Urbano. Cresce número de idosos na cidade de São Paulo [Internet]. São Paulo; 2011 [acesso em 2017 fev. 08]. Disponível em: http://smdu.prefeitura.sp.gov.br/informes urbanos/pdf/5.pdf

7. Mello Jorge MHP. Acidentes de trânsito no Brasil: um atlas de sua distribuição. São Paulo: Abramet; 2013.

8. Saraiva A. Homens lideram acidentes de trânsito, diz IBGE. Valor Econômico [Internet]. São Paulo; 2015 [acesso em 2017 fev. 06]. Disponível em: http://www.valor.com.br/ brasil/4077768/homens-lideram-acidentes-de-transito-dizibge

9. Toledo LF. 77\% dos mortos em acidentes de trânsito em SP são homens. O Estado de São Paulo [Internet]. São Paulo, 2016 [acesso em 2017 fev. 08]. Disponível em: http://saopaulo.estadao.com.br/noticias/geral,77-dos-mortos-emacidentes-de-transito-em-sp-sao-homens, 10000017822

10. Trânsito BR. O Portal do trânsito brasileiro [Homepage na Internet]. São Paulo [aceso em 2017 fev. 08]. Disponível em: http://www.transitobr.com.br/index2.php?id_conteudo=9 